\title{
DAYA SAING DI RUMAH SAKIT ISLAM FAISAL TAHUN 2017
}

\section{COMPETITIVENESS ASPECT AT FAISAL ISLAMIC HOSPITAL 2017}

\author{
Agustina Pujilestari ${ }^{1}$, Syahrir A. Pasinringi ${ }^{2}$, Sangkala ${ }^{3}$ \\ ${ }^{1}$ Program Studi Kesehatan Masyarakat Universitas Hasanuddin \\ ${ }^{2}$ Bagian Administrasi Rumah Sakit, Fakultas Kesehatan Masyarakat, Universitas \\ Hasanuddin \\ ${ }^{3}$ Bagian Administrasi Rumah Sakit, Fakultas Kesehatan Masyarakat, Universitas \\ Hasanuddin \\ Alamat Korespondensi: Agustina Pujilestari, SKM, Fakultas Kesehatan Masyarakat \\ Universitas Hasanuddin Makassar, Telp: 081242419913 \\ Email: agustina91.mars@gmail.com
}

\begin{abstract}
Abstrak
Daya saing merupakan kemampuan perusahaan untuk memperoleh pangsa pasar sehingga mampu bertahan menghadapi persaingan. Penelitian ini bertujuan untuk menganalisis daya saing di Rumah Sakit Islam Faisal tahun 2017. Penelitian ini menggunakan metode kualitatif dengan pendekatan studi kasus. Teknik pengumpulan data dilakukan dengan cara triangulasi. Informan sebanyak 4 orang yang dipilih menggunakan teknik snowball sampling. Penelitian ini menggunakan teori Porter's five forces sebagai acuan dalam menganalisis daya saing rumah sakit. Hasil penelitian menunjukkan bahwa daya saing Rumah Sakit Islam Faisal tergolong rendah terkait dengan persaingan antarrumah sakit, ancaman rumah sakit baru, kekuatan pasien, kekuatan supplier dan ancaman fasilitas pengganti. Kelima kekuatan tersebut memberikan ancaman yang kuat sehingga dapat menekan kemampuan daya saing rumah sakit, khususnya terkait persaingan antarrumah sakit karena rumah sakit tidak didukung oleh sumber daya manusia yang cukup, khususnya untuk tenaga kesehatan dan fasilitas penunjang medis yang kurang lengkap. Penelitian ini menyarankan bagi rumah sakit untuk melakukan analisis kebutuhan pasar melalui riset untuk mengetahui pelayanan yang dibutuhkan pelanggan, serta menyesuaikannya dengan sumber daya manusia,sarana dan fasilitas penunjang medis yang dibutuhkan untuk menarik pelanggan.
\end{abstract}

Kata Kunci: Daya Saing, Porter's Five Forces

\begin{abstract}
Competitiveness is a company's ability to gain market share so it could survived against the competition. This study aimed to analyze the competitiveness in Faisal Islamic Hospital in 2017. This study using a qualitative method with case study approach. Data collected by triangulation technique This study informant were 4 people selected using snowball sampling technique. This study using Porter's five forces theory as a reference in analyzing hospital competitiveness. The results show that the competitiveness of Faisal Islamic Hospital is low on threats from competition among the hospitals, new hospital threats, patient power, suppliers power and substitution threats from other health facilities. The five forces provide a strong threat to reduce the competitiveness of hospitals, especially about hospital competition because hospitals are not supported by adequate human resources, especially for medical staff and inadequate medical support facilities.. This research suggests for hospitals to analyze market needs through research to find out the customer needs, and adapt them to the human resources, facilities and medical support facilities were needed to attract customers.
\end{abstract}

Keywords: Competitiveness, Porter's Five Forces 


\section{PENDAHULUAN}

Banyak industri yang gagal mencapai tujuan yang telah ditetapkan sendiri karena tidak memiliki daya saing yang mampu menghadapi persaingan di pasar industri. Dinamika industri menjadi tantangan bagi para pemain industri untuk senantiasa menyesuaikan kemampuan sehingga memiliki kapasitas untuk terus bersaing dari waktu ke waktu. Memperoleh pasar yang lebih luas merupakan salah satu ciri bahwa organisasi tersebut memiliki daya saing yang kuat. Untuk membangun daya saing yang kuat, perusahaan atau sebuah organisasi industri harus menyusun strategi yang tepat untuk mampu menghadapi sifat persaingan yang dinamis, dan itu dimulai dengan mengenal kondisi lingkungan industri itu sendiri.

Rumah sakit merupakan salah satu organisasi publik yang didirikan dengan tujuan memberikan pelayanan kepada masyarakat. Di Indonesia sendiri rumah sakit mengalami pertumbuhan yang pesat dari waktu ke waktu. Data dari Dirjen Bina Upaya Kesehatan (Kemenkes RI, 2016) menunjukkan terdapat 1.367 rumah sakit di Indonesia untuk tahun 2015 (meningkat $8,83 \%$ dari tahun sebelumnya yg berjumlah $1256 \mathrm{RS}$ ), yang terdiri dari 805 rumah sakit pemerintah dan 562 rumah sakit swasta. Pertumbuhan rumah sakit di provinsi Sulawesi Selatan juga mengalami pertumbuhan yang signifikan sebesar $8,9 \%$ dari 90 rumah sakit pada tahun 2016 kemudian bertambah menjadi 98 rumah sakit pada tahun 2017 (Kemenkes RI, 2017). Kemudian di Kota Makassar sendiri saat ini terdapat 44 rumah sakit yang terdiri dari 13 rumah sakit milik pemerintah dan 31 rumah sakit milik swasta (Kemenkes RI, 2016).

Seiring dengan pertumbuhan tersebut maka terjadi persaingan yang ketat bagi rumah sakit untuk memenangkan pasar di industri rumah sakit. Kota Makassar menjadi pusat dari persaingan rumah sakit di Provinsi Sulawesi Selatan karena terdapat 53\% rumah sakit yang berada di kota Makassar. Banyak hal yang dilakukan oleh rumah sakit untuk menarik minat pelanggan agar memanfaatkan

rumah sakit tersebut mulai dari meningkatkan kualitas pelayanan, menyediakan peralatan medis yang canggih, menambah jenis pelayanan, pelayanan dari sumber daya manusia yang professional ataupun dengan mengadakan sarana dan prasarana yang modern.

Untuk dapat bertahan dalam jangka waktu yang panjang, sebuah organisasi harus dapat menghasilkan kinerja yang baik yaitu dengan memeberikan hasil kerja yang efektif dan efisien, serta tetap relevan terhadap stakeholder (Lusthaus dkk., 2002). Capaian kinerja tersebut juga dapat menjadi jawaban atas tekanan yang berasal dari pemerintah, badan asuransi maupun masyarakat yang menuntut adanya komitmen dari rumah sakit untuk dapat menyelenggarakan pelayanan yang sesuai dengan peraturan yang ada.

Day dan Wensley (1988) menyatakan bahwa perusahaan harus mampu mencapai tujuan akhirnya yaitu untuk dapat meningkatkan kinerja perusahaan. Untuk itu dibutuhkan sebuah sarana atau alat untuk mencapai tujuan akhir tersebut yaitu daya saing dari perusahaan itu sendiri. Hal ini sejalan dengan yang diungkapkan Porter (1990) bahwa daya saing sangat penting dalam menentukan keberhasilan bagi suatu industri. Penelitian yang dilakukan oleh Indiatsy, dkk (2014) menemukan bahwa terdapat terdapat hubungan positif yang kuat antara model five forces Porter dan Kinerja perusahaan. Kemudian penelitian yang dilakukan oleh Wibisono (2013) yang melakukan evaluasi terhadap tingkat daya saing RS Bakti Timah dengan menggunakan five forces Porter menemukan bahwa rumah sakit memiliki tingkat daya saing yang tinggi sehingga di masa depan dianggap mampu bertahan dan berkompetisi yang ditunjukkan dengan kinerja yang unggul.

Rumah Sakit Islam Faisal merupakan salah satu dari 14 rumah sakit kelas B yang ada di kota Makassar. Rumah Sakit Islam Faisal mempunyai kinerja yang lebih rendah di antara rumah sakit sekelas 
lainnya. Hal ini diindikasikan dengan tidak tercapainya BOR sesuai standar yang telah ditetapkan Depkes RI 60-85\% yakni hanya pada kisaran $54,18 \%$ dari tahun 2013-2015. Selain itu, Rumah Sakit Islam juga memiliki kunjungan pasien rawat jalan paling rendah di antara rumah sakit sekelas lainnya yakni sekitar 66 pasien perhari. Berdasarkan latar berlakang masalah tersebut maka tujuan penelitian ini adalah menganalisis daya saing di Rumah Sakit Islam Faisal pada tahun 2017.

\section{BAHAN DAN METODE}

Penelitian ini dilaksanakan di Rumah Sakit Islam Faisal Kota Makassar dari selama bulan November tahun 2017. Jenis penelitian adalah penelitian kualitatif melalui pendekatan studi kasus. Informan dipilih berdasarkann teknik snowball sampling sehingga terpilih 4 orang untuk menjadi informan pada penelitan ini.

Data yang digunakan pada penelitian ini adalah data primer, data sekunder, dan hasil observasi peneliti di lapangan. Data primer adalah data yang diperoleh langsung dari hasil wawancara yang diperoleh dari narasumber atau informan dan data sekunder adalah sebagai data pendukung data primer dari literatur dan dokumen serta data yang diambil dari suatu organisasi atau instansi yang terkait dengan penelitian berupa bahan bacaan, bahan pustaka, dan laporan-laporan penelitian. Kemudian data observasi adalah data yang diperoleh oleh peneliti dengan melakukan pengamatan langsung pada objek penelitian sesuai dengan kriteria informasi yang dibutuhkan. Proses analisis data dilakukan secara terus menerus dimulai dengan menelaah seluruh data yang tersedia dari berbagai sumber, yaitu dari wawancara, pengamatan yang sudah dituliskan dalam catatan lapangan, dokumen dan sebagainya sampai dengan penarikan kesimpulan (Moleong, 2009).

\section{HASIL}

\section{Persaingan antarrumah sakit}

Berdasarkan data dari Kemenkes RI (2017) diperoleh bahwa dari total 48 rumah sakit yang berada di Kota Makassar,
14 di antaranya adalah rumah sakit umum kelas B. Sesuai dengan data tersebut, berdasarkan hasil wawancara dengan informan diperoleh hasil bahwa rumah sakit yang dianggap sebagai pesaing yaitu rumah sakit sekelas yang ada di kota Makassar.

Kemudian terkait keunggulan rumah sakit pesaing dibanding Rumah Sakit Islam Faisal berdasarkan hasil wawancara dengan para informan diperoleh informasi bahwa rumah sakit pesaing memiliki manajemen yang lebih professional, sumber daya manusia khususnya dokter yang lebih komitmen, sarana-prasarana yang lebih modern, serta fasilitas penunjang medis yang lebih lengkap. Kemudian data yang diperoleh bahwa Rumah Sakit Islam Faisal belum memiliki tenaga kesehatan yang adekuat dengan jumlah dokter yang lebih sedikit jika dibandingkan dengan rumah sakit pesaing, dengan rincian 14 dokter umum, 35 dokter dokter spesialis, 3 dokter gigi, 2 dokter spesialis gigi, rasio tenaga perawat dengan tempat tidur 2:3 (standar Kemenkes 1:1 ), dan tenaga apoteker 2 orang. Dari hasil penelitian ini juga Rumah Sakit Isla Faisal tidak memiliki fasilitas penunjang medis yang lengkap seperti CT-Scan, dan MRI yang umumnya dimiliki oleh rumah sakit pesaing yang masih sekelas.

Hasil analisis bedasarkan uraian data tersebut disesuaikan dengan kriteria yang ditentukan oleh Porter (2008) diperoleh hasil bahwa daya saing terkait persaingan antar rumah sakit tergolong kuat, yang berarti persaingan antarrumah sakit memiliki kekuatan yang besar untuk mengancam dan menekan daya saing rumah sakit.

\section{Ancaman rumah sakit baru}

Berdasarkan hasil wawancara dengan informan diperoleh informasi bahwa untuk masuk ke dalam industri perumahsakitan terbilang relatif, bergantung pada kemampuan rumah sakit baru untuk memasarkan pelayanan dan memenuhi kebutuhan pelanggan. Namun, pada umumnya rumah sakit baru yang ada 
datang dengan konsep teknologi yang lebih canggih serta fasilitas yang lebih modern. Dari segi kebijakan pemerintan provinsi Sulawesi Selatan sendiri telah menetapkan beberapa kebijakan yang mengatur izin untuk mendirikan dan mengoperasikan rumah sakit kelas B.

Pasien yang telah berobat ke Rumah Sakit Islam Faisal memiliki loyalitas terhadap rumah sakit yang diperkuat dengan data yang menunjukkan bahwa rumah sakit didominasi oleh pasien lama yang berjumlah di atas $50 \%$ dari total keseluruhan pasien yang ada.

Hasil analisis berdasarkan uraian informasi tersebut disesuaikan dengan kriteria oleh Porter (2008) diperoleh bahwa tingkat ancaman terkait masuknya rumah sakit baru ke dalam industri tergolong sedang. Hal ini berarti rumah sakit baru cukup memberikan ancaman terhadap daya saing rumah sakit.

\section{Kekuatan Supplier}

Data dari hasil penelitian menunjukkan bahwa saat ini Rumah Sakit Islam Faisal bekerjasama dengan 16 supplier obat, 7 supplier alat kesehatan, dan 16 supplier BHP (Bahan Habis Pakai). Rumah sakit cenderung tidak bergantung pada supplier yang ada karena banyaknya pilihan supplier yang ada. Berdasarkan data dari Dinkes Provinsi Sulsel diperoleh bahwa pada tahun 2016 terdapat 149 perusahaan farmasi di kota Makassar.

Hasil wawancara dengan informan bahwa untuk kualitas produk dari supplier disesuaikan dengan standar yang diatur oleh BPJS karena rumah sakit merupaka mitra kerja sama yang harus menyesuaikan dengan perjanjian yang telah disepakati. Rumah Sakit Islam Faisal berusaha bekerjasama dengan supplier yang menawarkan harga yang paling terjangkau sehingga perpindahan rumah sakit ke supplier lain dinilai akan terasa lebih mahal.

Hasil analisis dari informasi yang ada disesuaikan dengan kriteria oleh Porter (2008) diperoleh bahwa tingkat ancaman Rumah Sakit Islam Faisal terkait kekuatan supplier tergolong sedang. Hal ini berarti supplier cukup memberikan ancaman dan dapat menekan saya saing rumah sakit.

\section{Kekuatan Pasien}

Hasil penelitian ini menunjukkan bahwa pertumbuhan pasien di Rumah Sakit Islam Faisal mencapai $15-17 \%$ dari tahun 2014-2016. Pasien BPJS merupakan kelompok pasien yang paling mendominasi pembelian jasa di rumah sakit, bahkan mencapai $80 \%$ pada tahun 2016. Biaya beralih pelayanan bagi pasien, untuk biaya pelayanan di Rumah Sakit Islam Faisal dibanding dengan rumah sakit pesaing tidak terlalu memperlihatkan perbedaan yang signifikan terkait tarif pelayanan. Rumah Sakit merupakan institusi dengan produk layanan yang terstandardisasisehingga rumah sakit sejenis dan sekelas cenderung memiliki penawaran pelayanan yang sama, sehingga pasien sebagai pelanggan semakin leluasa menentukan pilihan rumah sakit.

Hasil analisis berdasarkan data yang kemudian dibandingkan dengan kriteria Porter (2008) diperoleh bahwa tingkat ancaman terkait kekuatan pasien tergolong kuat. Hal ini berarti bagi Rumah Sakit Islam Faisal, pasien sangat kuat untuk menekan kemampuan daya saing rumah sakit.

\section{Ancaman Fasilitas Kesehatan Pengganti}

Berdasarkan hasil wawancara mendalam dengan manajer rumah sakit terkait keberadaan fasilitas kesehatan pengganti rumah sakit sebagai ancaman, diperoleh informasi bahwa keberadaan fasilitas kesehatan memiliki potensi menjadi ancaman bagi rumah sakit, Rumah Sakit Ibu dan Anak. Namun untuk keberadaan fasilitas kesehatan seperti klinik pertama justru dapat mendukung rumah sakit.

Hasil wawancara dengan manajer rumah sakit diperoleh pernyataan bahwa biaya yang dihabiskan untuk pengobatan di rumah sakit khusus akan lebih mahal apabila dibandingkan dengan pengobatan di rumah sakit umum, karena rumah sakit khusus memiliki peratalan penunjang yang lebih lengkap karena menyajikan 
pelayanan yang lebih spesifik dibanding dengan rumah sakit umum.

Hasil analisis berdasarkan data dibandingkan dengan kriteria Porter(2008) diperoleh hasil bahwa tingkat ancaman fasilitas kesehatan pengganti tergolong sedang. Ancaman terkait fasilitas kesehatan pengganti tergolong sedang berarti fasilitas kesehatan pengganti memiliki cukup kekuatan untuk memberikan ancaman sehingga mengancam daya saing rumah sakit.

\section{Daya Saing Rumah Sakit Islam Faisal}

Semakin lemah kelima kekuatan di atas maka semakin tinggi pula tingkat daya saing rumah sakit. Pada hasil analisis di atas dapat dilihat bahwa ancaman yang berasal dari rumah sakit baru, kekuatan supplier dan ancaman fasilitas kesehatan pengganti (subtitusi) tergolong sedang. Kemudian untuk ancaman yang ditimbulkan akibat persaingan antarrumah sakit serta kekuatan yang dimiliki pasien tergolong kuat.

Pada hasil analisis di atas maka dapat diketahui bahwa dari kelima kekuatan terbilang cukup kuat untuk memberikan mempengaruhi rumah sakit untuk meraih pangsa pasar di industri rumah sakit. Sehingga tingkat daya saing Rumah Sakit Islam Faisal berada pada kategori "Lemah".

\section{PEMBAHASAN}

Persaingan antarrumah sakit menjelaskan tentang intensitas kompetisi antara perusahaan yang sudah berdiri dalam satu sektor industri yang ada saat ini. 13 dari 18 rumah sakit umum tipe B yang ada di Sulawesi Selatan, berada di Kota Makassar. Hal ini menandakan bahwa sekitar $70 \%$ persaingan rumah sakit umum tipe B berpusat di kota Makassar. Lebih dari $50 \%$ didominasi oleh rumah sakit umum swasta.

Hasil dari analisis yang dilakukan, diperoleh bahwa aspek persaingan antarrumah sakit berada dalam tingkat kuat. Hal ini berarti tingkat persaingan antarrumah sakit yang ada saat ini mampu memberikan tekanan terhadap daya saing
Rumah Sakit Islam Faisal. Sejalan dengan hasil penelitian ini, Budi (2015) melakukan analisis daya saing pada sebuah perusahaan telekomunikasi dan menemukan bahwa tingkat persaingan antarperusahaan berada dalam tingkat sedang. Hal ini sebabkan karena banyaknya jumlah pesaing yang ada serta penawaran harga yang relatif sama antarperusahaan telekomunikasi yang ada.

Menurut Pringle dan Huisman

(2011) persaingan antarperusahaan yang tinggi akan membatasi tingkat profitabilitas yang mampu dicapai suatu industri. Ini juga yang menyebabkan tingkat persaingan antarperusahaan merupakan faktor terkuat dari kelima faktor yang ada (Porter, 2008). Tingkat persaingan antarrumah sakit yang berada pada kategori kuat pada hasil analisis penelitian ini, memberikan gambaran bahwa Rumah Sakit Islam Faisal harus mengembangkan daya saing sehingga mampu mencapai target pasar yang lebih luas dan meningkatkan profitabilitas.

Pesaing baru yang memasuki pasar dapat mengancam atau mengurangi pangsa pasar dan keuntungan pesaing yang ada dan dapat mengakibatkan perubahan pada kualitas produk atau tingkat harga yang ada (Wilkinson, 2013). Hasil dari analisis yang dilakukan, diperoleh bahwa aspek ancaman rumah sakit baru tergolong sedang. Hal ini berarti tingkat ancaman rumah sakit baru yang ada saat ini cukup memberikan pengaruh tekanan terhadap daya saing Rumah Sakit Islam Faisal.

Hasil ini sejalan dengan penelitian yang dilakukan oleh Wibisono (2013) pada RS Bakti Timah dimana tingkat ancaman pesaing baru tergolong sedang, yang disebabkan karena meskipun memiliki pasien yang loyal yang dapat dibuktikan dengan kepuasan pasien, namun rumah sakit baru pada umumnya didominasi oleh pihak swasta dengan 
kemampuan modal yang memadai sehingga berpeluang menawarkan sarana dan prasarana yang lebih baik dari rumah sakit yang sebelumnya.

Perihal ancaman rumah sakit baru merupakan aspek dalam melakukan analisis lingkungan eksternal dengan melihat seberapa besar hambatan yang harus dihadapi oleh rumah sakit baru untuk memasuki industri perumahsakitan yang ada. Semakin besar hambatan yang dihadapi, maka akan semakin sulit pula sebuah rumah sakit baru untuk memasuki lingkungan industri, dan begitu pula sebaliknya. Pendatang baru ke industri membawa kapasitas baru dan keinginan untuk meraih pangsa pasar yang memberi tekanan pada harga, biaya, dan tingkat investasi yang diperlukan untuk bersaing. (Pringle dan Huisman, 2011).

Hasil dari analisis yang dilakukan diperoleh bahwa tingkat kekuatan supplier tergolong sedang. Hal ini berarti supplier masih cukup memiliki pengaruh untuk memberikan tekanan terhadap daya saing Rumah Sakit Islam Faisal. Hasil penelitian ini sejalan dengan penelitian yang dilakukan Cheng (2013) pada industri perhotelan di Hongkong, menemukan bahwa kekuatan yang dimiliki supplier berada pada kategori sedang. Hal ini karena bagi hotel, terdapat banyak pilihan supplier yang dapat menggantikan supplier yang ada saat ini. Namun, tidak dapat dipungkiri juga bahwa industri perhotelan bukan satu-satunya pasar pelanggan bagi supplier. Tingkat kekuatan yang dimiliki supplier menjadikan supplier menjadi bagian tetap perlu membutuhkan fokus bagi para manajer untuk mengendalikan para supplier sehingga tidak menjadi ancaman yang dapat menekan rumah sakit. Supplier yang kuat menandakan supplier memiliki kemampuan untuk menentukan nilainya sendiri, sehingga supplier dapat mengendalikan harga produk terhadap pembeli (Pringle dan Huisman, 2011).

Apabila rumah sakit mendapati bahwa supplier berada dalam tingkatan yang dapat mempengaruhi rumah sakit, maka rumah sakit sebagai pihak yang bekerjasama dengan supplier mungkin perlu mengakhiri kerjasama tersebut atau beralih ke yang lain untuk menghindari didikte oleh keinginan supplier (Martin, 2014).

Hasil analisis dari penelitian yang dilakukan diperoleh bahwa tingkat kekuatan pasien tergolong kuat. Hal ini menandakan bahwa pasien memiliki kemampuan untuk menekan rumah sakit untuk memberikan penawaran pelayanan dan harga yang lebih menarik dari para pesaing. Hal ini sejalan dengan penelitian yang dilakukan oleh Tehrani dan Rahmani (2014) bahwa kekuatan pasien menjadi faktor yang paling kuat di antara kelima faktor yang ada dalam mempengaruhi hasil penjualan dan pangsa pasar sehingga perlu mendapat fokus yang lebih dari perusahaan.

Kekuatan pembeli (pasien) menjelaskan seberapa besar tekanan pembeli dapat mempengaruhi bisnis. Apabila satu pembeli mempunyai dampak yang cukup besar untuk memengaruhi volume dan marjin perusahaan, pembeli tersebut memiliki kekuatan yang besar. Rumah Islam Faisal membagi pasien ke dalam 3 kelompok berdasarkan pada metode pembayaran pasien yaitu pasien BPJS, pasien umum, dan lain-lain. Pasien BPJS yang mencapai $80 \%$ dari total keseluruhan pasien membuat posisi pasien semakin kuat di lingkungan industri rumah sakit, sedangkan pasien umum hanya berada pada kisaran $18 \%$ dari total keseluruhan kunjungan. Dominasi kelompok pasien tersebut membuat rumah sakit sangat bergantung pada pasien BPJS. Kebergantungan tersebut tentunya semakin menjadi ancaman bagi profitabilitas rumah sakit karena pasien memiliki kekuatan dalam menekan rumah sakit.

Rumah sakit merupakan salah satu fasilitas kesehatan tingkat lanjut yang memiliki banyak regulasi yang mengaturnya, seperti standar pelayanan yang telah ditetapkan oleh Kementerian Kesehatan dan disesuaikan dengan klasifikasi/tipe rumah sakit tersebut. Dalam hal ini rumah sakit umum tipe 
memiliki produk dan layanan yang terstandardisasi, sehingga cenderung memiliki jenis produk/layanan yang nyaris sama, dengan kata lain pelanggan bebas menentukan pilihan rumah sakit yang akan digunakan untuk mendapatkan pelayanan. sebuah produk akan layak menjadi sebuah pengganti apabila produk tersebut mampu memenuhi fungsi yang sama dengan produk yang digantikannya (Wipperfurth dkk., 2010). Hal ini berarti bagi fasilitas kesehatan lain, untuk menjadi sebuah produk subtitusi/pengganti dari rumah sakit, maka fasilitas kesehatan tersebut harus mampu memberikan pelayanan kesehatan yang sama dengan rumah sakit. Dalam hal ini rumah sakit kelas B merupakan fasilitas kesehatan yang menyediakan pelayanan spesialis mungkin akan terancam dengan keberadaan rumah sakit khusus dan klinik dokter spesialis. Di kota Makassar saja sedikitnya terdapat 120 klinik dan 28 rumah sakit khusus yang terdiri dari 21 RSIA, 3 RS bersalin, 1 RS kusta, 1 RS Jiwa, dan 2 RS Gigi dan mulut (Ditjen Yankes Kemenkes RI, 2017).

Hasil dari analisis yang dilakukan peneliti diperoleh bahwa tingkat ancaman fasilitas kesehatan pengganti tergolong sedang. Hal ini berarti fasilitas kesehatan pengganti cukup memiliki pengaruh yang dapat mengancam daya saing rumah sakit.

Hasil tersebut sejalan dengan penelitian yang dilakukan oleh Cheng (2013) pada industri perhotelan di Hongkong. Hasil penelitiannya menemukan bahwa ancaman dari subtitusi terbilang sedang karena meskipun sepenuhnya tidak sama tapi jumlah yang menggunakan pelayanan pada subtitusi akan sangat disayangkan. Padahal itu adalah potensi pasar yang akan berguna bagi perusahaan apabila dikelola dengan baik. Dengan tidak adanya faktor lain seperti loyalitas merek atau diferensiasi, pilihan untuk beralih tidak akan sulit (Martin, 2014).

Hasil analisis daya saing dengan memperhatikan ancaman dari kelima kekuatan menurut Porter, ditemukan bahwa Daya Saing Rumah Sakit Islam Faisal berada dalam kategori Lemah. Hal ini menandakan banyaknya ancaman yang dapat mempengaruhi kemampuan rumah sakit memperoleh pasar untuk dapat bertahan besaing di masa yang akan datang. Namun masih ada beberapa peluang yang membuat Rumah Sakit Islam Faisal mampu bertahan dalam menghadapi persaingan di lingkungan industri rumah sakit.

Porter (2008) menjelaskan apabila
industri tidak menarik memiliki
karakteristik yaitu ancaman pendatang
baru tinggi, kemudian kekuatan tawar
menawar sangat kuat, kekuatan tawar
pembeli sangat kuat, ancaman produk
pengganti tinggi, akhirnya, intensitas
persaingan antar kompetitor industri tinggi,
serta produk atau layanan pelengkap tidak
tersedia. Apabila kekuatan persaingan
seperti yang dijelaskan di atas, maka
industri ini tidak menarik dan ada potensi
keuntungan yang terbatas (Wilkinson,
2013).

\section{KESIMPULAN DAN SARAN}

Secara keseluruhan daya saing Rumah Sakit Islam Faisal dianalisis menggunakan Porter's Five Forces menunjukkan bahwa daya saing rumah sakit tergolong lemah. Tidak mampunya rumah sakit menyaingi keunggulan rumah sakit pesaing juga produk layanan yang kurang terdiferensiasi dengan yang lain membuat pelanggan semakin kuat sehingga leluasa dalam membuat pilihan pada rumah sakit yang akan digunakan. Penelitian ini menyarankan bagi rumah sakit untuk melakukan analisis kebutuhan pasar melalui riset untuk mengetahui pelayanan yang dibutuhkan pelanggan, serta menyesuaikannya dengan sumber daya manusia,sarana dan fasilitas penunjang medis yang dibutuhkan untuk menarik pelanggan.

\section{DAFTAR PUSTAKA}

Budi, J. D. (2015). Analisis Strategi Keunggulan Bersaing Pada PT. Telekomunikasi Indonesia, Tbk. 
Witel Jatim Selatan Malang (Skripsi). Fakultas Ekonomi dan Bisnis. Malang, Universitas Brawijaya.

Cheng, D. S. Y. (2013). "Analyze the Hotel Industry in Porter Five Competitive Forces." The Journal of Global Business Management 9(3): 52-57.

Day, G.S. and R. Wensley (1988). "Assessing Advantage: A Framework for Diagnosing Competitive Superiority". Journal of Marketing. 52: 1-20

Indiatsy, C. M., dkk. (2014). "The Application of Porter's Five Forces Model on Organization Performance: A Case of Cooperative Bank of Kenya Ltd." European Journal of Business and Management 6(16): 75-86.

Kemenkes RI.(2016). "Data RS Online." 2016, from http://sirs.yankes.kemkes.go.id/rson line/report/.

Kemenkes RI.(2017). "Data RS Online." 2017, from http://sirs.yankes.kemkes.go.id/rson line/report/.

Lusthaus, C., dkk. (2002). Organizational Assessment: A Framework for Improving Performance. Ottawa, International Development Research Centre.

Martin (2014). "Bargaining Power Of Buyers: Porter's Five Forces Model." from https://www.cleverism.com/bargain ing-power-of-buyers-porters-fiveforces-model/.

Menkes (2014). Permenkes no.56 tentang Klasifikasi dan Perizinan Rumah Sakit. K. Kesehatan.

Moleong, L. J. (2005). Metodologi Penelitian Kualitatif. Bandung, Remaja Rosdakarya.

Porter, M. E. (1990). Competitive Advantage. Creating and Suistaining Superior Performance. New York, The Free Press.

Porter, M. E. (2008). "The Five
Competitive Forces that Shape Strategy." harvard business review: 24-41.

Pringle, J. dan J. Huisman (2011). "Understanding Universities in Ontario, Canada: An Industry Analysis Using Porter's Five Forces Framework." Canadian Journal of Higher Education 41(3): $36-58$.

Tehrani, M. B. and F. Rahmani (2014). "Evaluation Strategy Michael Porter's five forces model of the competitive environment on the dairy industry (Case Study: Amoll Haraz Dvshh dairy company)." American Journal of Engineering Research (AJER) 03(05): 80-85.

Wibisono, M. S. dan M. Hamsal (2013). "Business Strategy Development and Business Model RS .Bakti Timah ( RSBT ) Groups Pangkal Pinang under Bakti Timah Foundation ( YBT ) become PT. RS Bakti Timah As An Existance Of Diversification Effort From PT.Timah (PERSERO) TBK." The Indonesian Journal of Business Administration 2(16): 2010-2019.

Wilkinson, J. (2013). "Porter's Five Forces of Competition." Retrieved 12 Desember, 2017, from https://strategiccfo.com/portersfive-forces-of-competition/.

Wipperfurth, A., dkk. (2010). Microeconomics of Competitiveness: Minnesota's Medical Devices Cluster, Department of Employment and Economic Development.

Scull, T. M.(2010). Adolescents' Mediarelated Cognitions and Substance Use in the Context of Parental and Peer Influences. J Youth Adolesc 39(9): 981-998, 39. 